\title{
Experimental study of surface defects on automotive doors during flanging and their numerical prediction
}

\author{
A. Le Port ${ }^{1,2}$, S. Thuillier ${ }^{1,2}$, P.-Y. Manach ${ }^{1,2, a}$, and J. Garabed ${ }^{3}$ \\ 1 Université de Bretagne-Sud, LIMATB, rue de Saint Maudé, BP 92116, 56321 Lorient, France \\ 2 Université européenne de Bretagne, France \\ 3 PSA Peugeot Citroën, DTI/DITV/ICPE/CEMB, BP 95217, F-35652 Le Rheu, France
}

\begin{abstract}
Surface defects can develop on automotive exterior panels after drawing and flanging steps, during springback and may alter significantly the vehicle quality. These defects are characterized by a depth below $0.5 \mathrm{~mm}$ and are then difficult to detect or predict numerically. This study focuses on a L-shaped part designed on purpose to reproduce at a small scale surface defects that occur after flanging. Dimensions of these defects are measured from profiles obtained with a tridimensional measuring machine. The investigation of the influence of the flanging height and flanging speed shows than neither of these parameters have impact on the surface defect. The numerical simulation of the flanging process predict the surface defect but with a lower depth than the experimental defect.
\end{abstract}

\section{Introduction}

Nowadays tool makers for the automotive industry are concerned about surface defect problems occurring on opening parts like doors. Such parts are usually performed in several stages (4-5) including deep drawing, trimming and flanging. Moreover, springback occurs in-between the different steps. The process parameters and tool geometries are determined from the numerical simulation of the deep drawing stage. However, it is noticed from experiments that surface defects, which are characterized by a local inversion of the curvature, develop during springback following the drawing stage, but also the flanging stage. At the moment the parameters governing the severity of surface defects are not well identified, resulting in many trials to suppress them. Potential areas can sometimes be detected numerically regarding the small amount of plastic strain or the sign of principal stress values but these criteria fail in a certain number of cases.

A few studies can be found in the literature dealing with the numerical prediction of shape defects in deep drawing. The most common type of defects is teddy bear ears in the vicinity of the door handle [1] or the fuel tank [2]. At the moment in industry, stamped parts are investigated by hand in order to quantify the defects. And there exists an empirical rule which relates the magnitude of the defect to a scale which ranges from non-visible defects after painting up to non-acceptable defects. In order to rely on less subjective criteria, based also on a quantified measure, tool makers are really keen to introduce reliable criteria for the numerical simulation of surface defects.

A surface defect is an irregularity in the reflexion of the light on a supposedly continuous surface. Currently it is still difficult to measure it, because of its appearance on curved surface. In this study a surface defect on a door upper-corner is observed and analysed by several methods. A non-destructive method is to apply oil on the surface and observe the light reflexion in a neon-chamber room (Fig. 1(a)). To visualise precisely the boundaries of a depression the surface is scratched (Fig. 1(b)). The area of the defect is also digitalized with an optical fringe projecting device (Atos, GOM) that allows to

\footnotetext{
${ }^{a}$ e-mail: pi erre-yves. nanach@ini v-ubs. fr
} 
characterize the defect with a depth of $0.4 \mathrm{~mm}$, a length of $100 \mathrm{~mm}$ and a width of $30 \mathrm{~mm}$, which corresponds to a severe surface defect needing to be fixed.

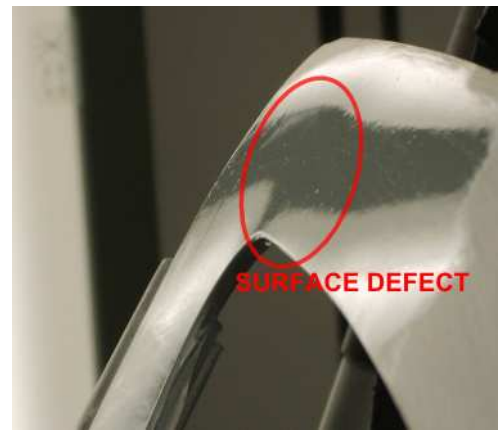

(a) neon chamber visualization

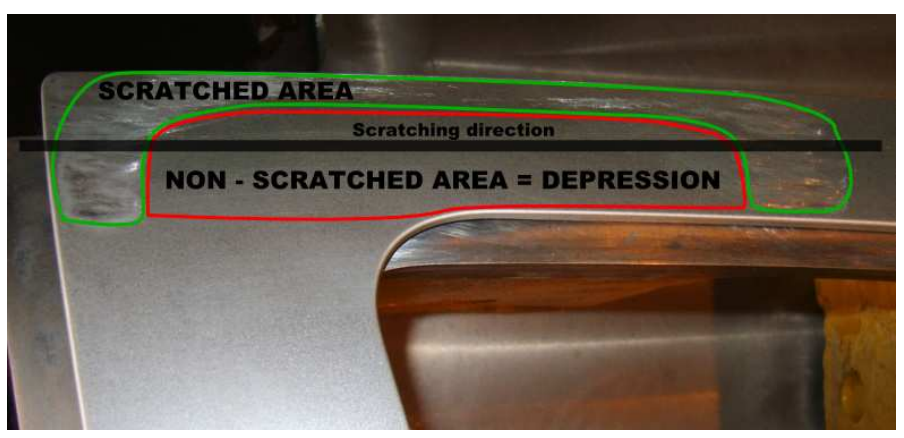

(b) wheatstone scratching

Fig. 1. Different methods to highlight a surface defect

This study presents the results obtained with a flanging device which aims to reproduce a uppercorner surface defect on a simplified geometry. Several tests have been performed to check reproducibility and study the influence of the flanged height and the flanging speed. Results of a test in a reference configuration are compared with those of a finite-element numerical simulation. Finally conclusions and perspectives are given for this study.

\section{Experimental tests}

Surface defects observations on door-upper corners lead to the conclusion that they mainly appear at the flanging stage when the blank is released from the tools. Also it is noticed that surface defects happen on rather low-curved surfaces, so a flat blank is used for simplified processing.

The flanging device has been designed so as to reproduce the same kind of defect that appears in the door-upper corner region at the flanging stage. This device aims to be compact, modular and easily processed. Fig. 2(a) illustrates the flanging device set on a Zwick-Roell BUP200 testing machine. It is composed of a flanging blade, a blank-holder and a die, each component being divided in a fix part attached to the testing machine and a removable part that allows geometrical modularity. The geometrical features of the tools used are presented in Tab. 1. The geometry of the sample with a flanging height of $5 \mathrm{~mm}$ is defined in Fig. 2(b), it consists of a disc with a missing quarter obtained by laser cutting. The tested flanging height are 3,4 and $5 \mathrm{~mm}$, in every case this height is reduced near the corner radius to avoid the fracture of the sample. The recorded raw data are the blade displacement, the flanging force and the blank-holder force.

Table 1. Geometrical features of the flanging tools.

\begin{tabular}{llll}
\hline blade radius & flanging radius & die-flange clearance & corner radius \\
\hline $2 \mathrm{~mm}$ & $0.5 \mathrm{~mm}$ & $0.67 \mathrm{~mm}$ & $4 \mathrm{~mm}$ \\
\hline
\end{tabular}

The results have been obtained using dual phase DP500 steel sheets with a thickness of $0.6 \mathrm{~mm}$. This material has been characterized using uniaxial tensile tests, biaxial expansion tests and shearing tests. Fig. 3 shows the stress-strain corellation between experimental results and an optimised numerical model using Hill's 1948 anisotropic yield criterion and isotropic hardening. Plastic anisotropy coefficients at $0^{\circ}, 45^{\circ}$ and $90^{\circ}$ are $0.87,1.04$ and 1.03 respectively. 


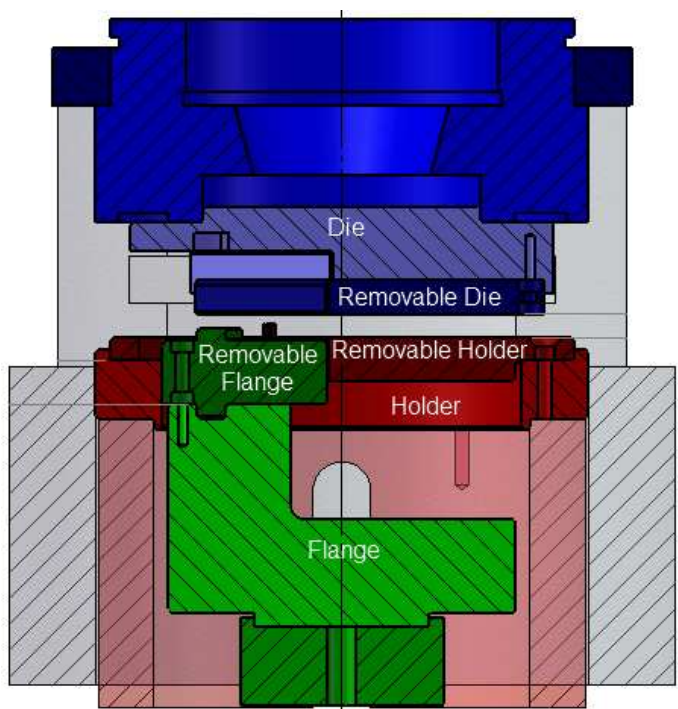

(a) Transversal cut view of the flanging device

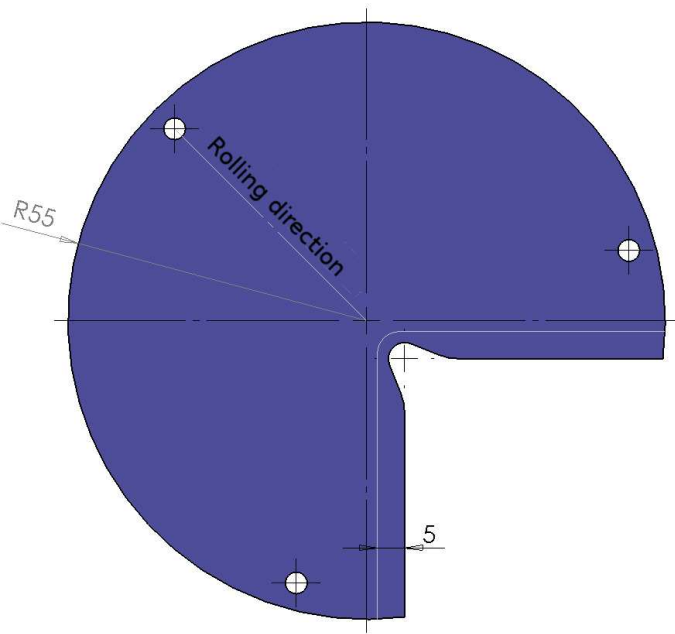

(b) Definition drawing of a blank with $5 \mathrm{~mm}$ flanging height

Fig. 2. Flanging device and geometry of the blank

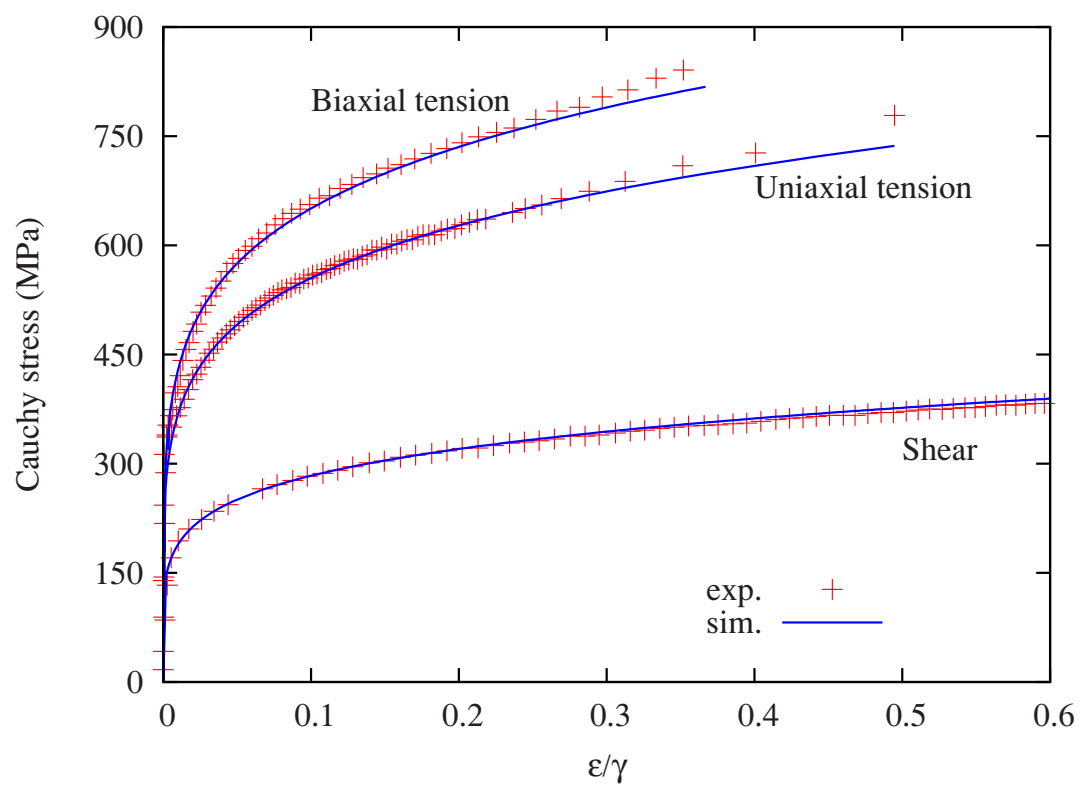

Fig. 3. Comparison of the flow stress between model predictions and experiments for uniaxial tension, simple shear (both in RD) and biaxial expansion, for DP500.

The blanks have been measured on a Brown\&Sharpe $₫$ MicroXcel pfx 4.5.4 three-dimensional measuring machine with an estimated accuracy of $7 \mu \mathrm{m}$. The blank is positionned on a dedicated set up thanks to its three holes and its surface is scanned every millimeter. Blanks are supposed to have a flat initial surface, but because of internal stress in the rolled sheet they exhibit an initial curvature. Thus samples are measured before and after the flanging operation so as to substract the initial curvature to 
the flanged sample. For this processing the displacement in the $x y$ plane is assumed to be negligible in the considered area.

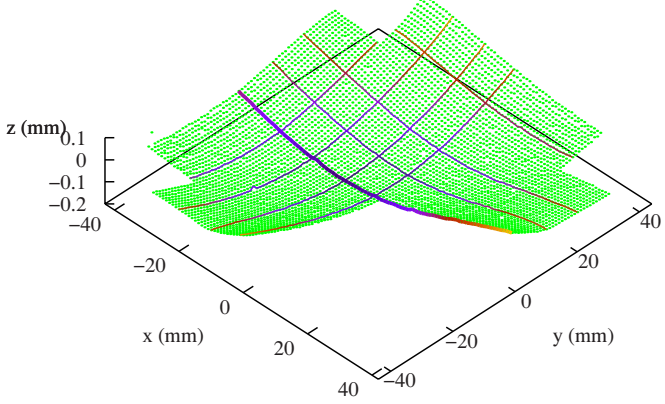

(a) initial surface

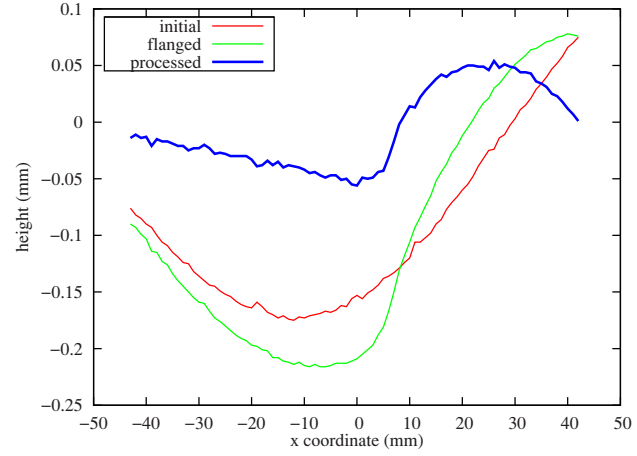

(b) Profiles along the $x$ axis at the coordinate $y=-1$ for an initial, flanged and processed blank

Fig. 4. Geometrical processing of the blanks

Moreover the symmetry of the geometry is checked by plotting so called symmetric profiles defined on Fig. 5(a). Their origin is the symmetry line (rolling direction in Fig. 2(b)), the negative coordinate corresponds to the profile along the $y$ direction and the positive coordinate is along the $x$ direction. Fig. 5(b) shows the symmetric profiles at the postion $-1 \mathrm{~mm}$ for two tests, pointing out that the test 4 has a poor symmetry and test 5 an acceptable symmetry.

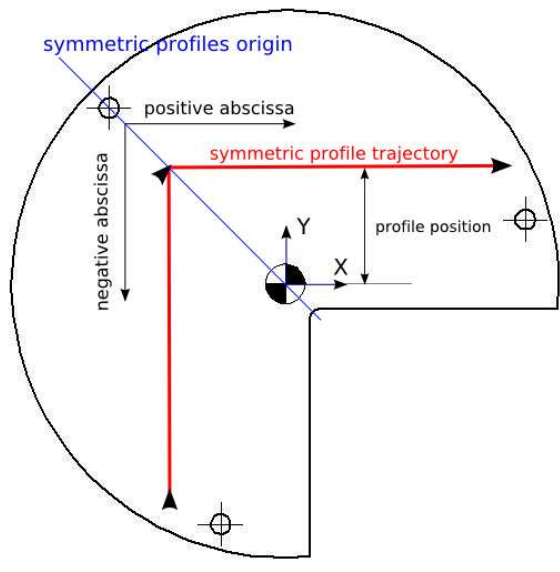

(a) profiles definition

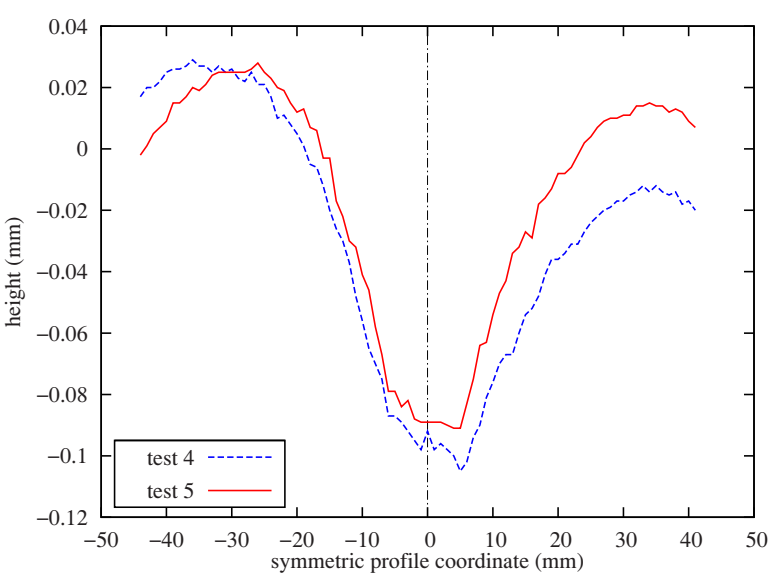

(b) profiles at the position of $-1 \mathrm{~mm}$ for two tests

Fig. 5. Definition and example of use of symmetric profiles

Surface defects are characterized by plotting parallel profiles along a specified direction. The depth and length are identified on the profile closest to the flanged edge and the width is approximated by identifying the closest profile without defect. 


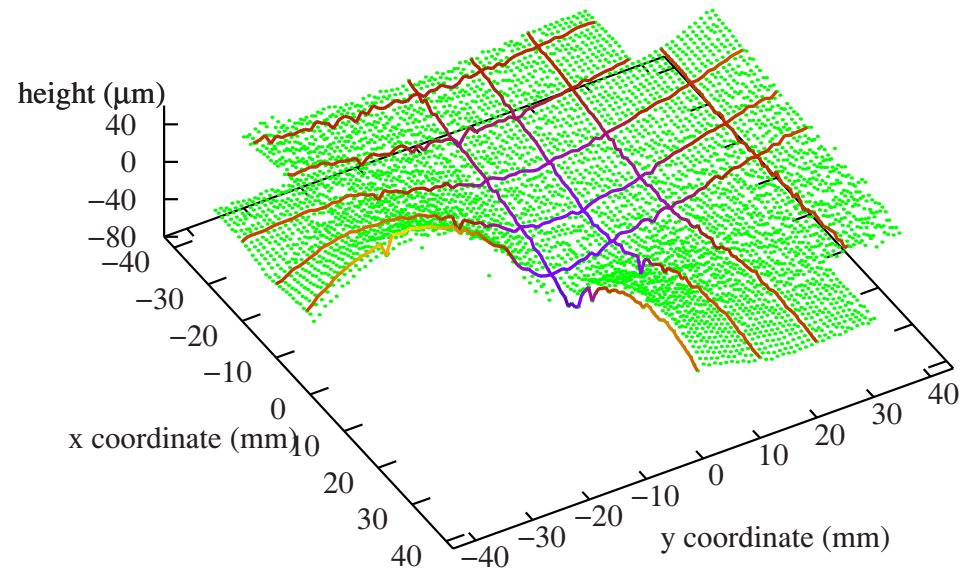

Fig. 6. profiles along $x$ and $y$ axis and global scanned surface of the reference blank

The shape of the defect can be observed in Fig. 6 where profiles along $x$ and y axes are plotted over the global scanned surface of the blank. It consists of a depression in the corner radius area and two bulges along the flanged edges. By plotting profiles along the $x$ axis for several $y$ values (Fig. 7) the surface defect presents a depth of $80 \mu \mathrm{m}$, a length of $70 \mathrm{~mm}$ and an approximate width of $36 \mathrm{~mm}$. This defect has been rated as not severe but needing to be fixed by experts from PSA Peugeot Citroën.

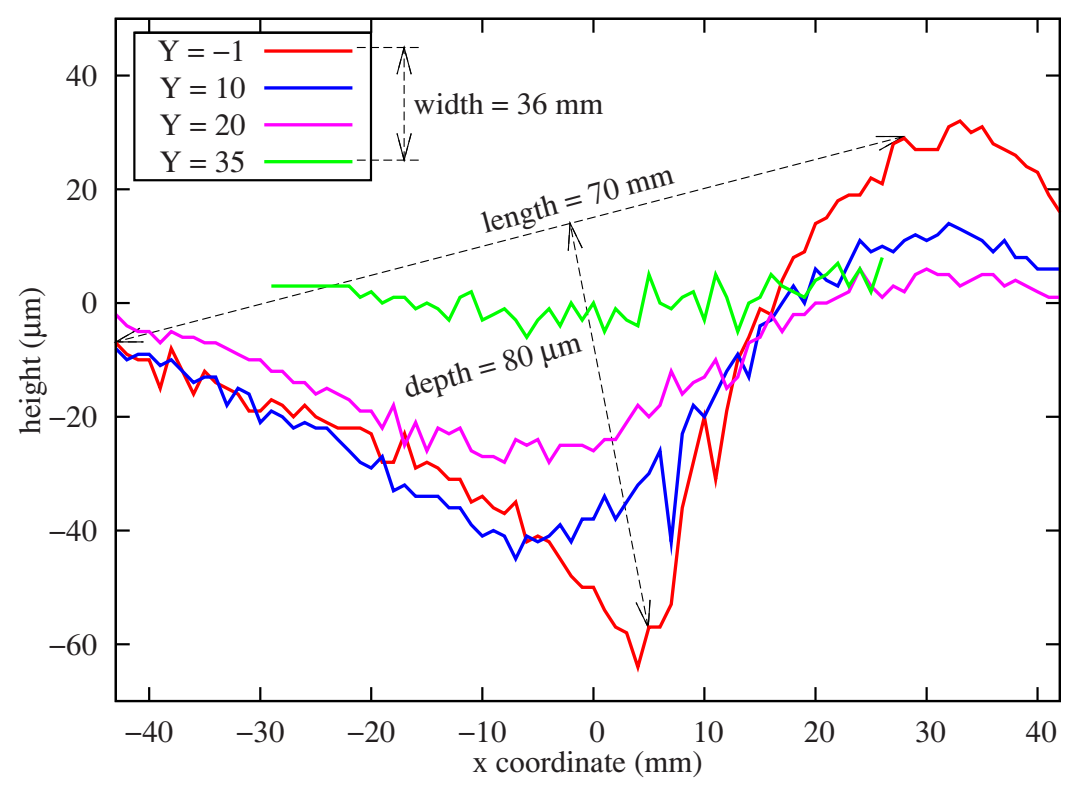

Fig. 7. profiles along $x$ axis for the reference blank for different $y$ values 


\section{Results and discussion}

The influence of two parameters has been investigated: the flanged height and the flanging speed, in addition the reference configuration has been compared to a numerical simulation.

\subsection{Flanging height influence}

To study the influence of the flanging height, the values of 3, 4 and $5 \mathrm{~mm}$ have been chosen, nevertheless the corner radius always has the same geometry with a reduced height (Fig. 2(b)). Fig.8(a) shows the flanging force versus punch displacement with two reproductible curves for each flanging height. It is observed that there is very little difference in the peak of effort, indeed the corner-radius region has the same geometry for all the flanging heights, and this is the region that bears the maximum strain and stress. The difference observed after the punch displacement of $7 \mathrm{~mm}$ is assumed to be due to the springback effort of the bent edges once flanged. If the springback effort that will make the edges open is assimilated to a torque, a shorter edge will tend to apply more pressure on the tools, explaining why the sample with the shortest edge needs a higher effort at the end of the flanging operation.

So as to compare the geometric features of the surface defect for each flanging height, the profile "y $=-1$ " is plotted on Fig. 8(b) with two reproductible curves by edge height. This profile has been chosen because it gives two of the three characteristics of a surface defect: the depth and the length, thus it is the most representative. In spite of slight vertical translations between the curves they all exhibit a very similar shape and do not allow to identify an influence of the edge length on the geometry of the surface defect.

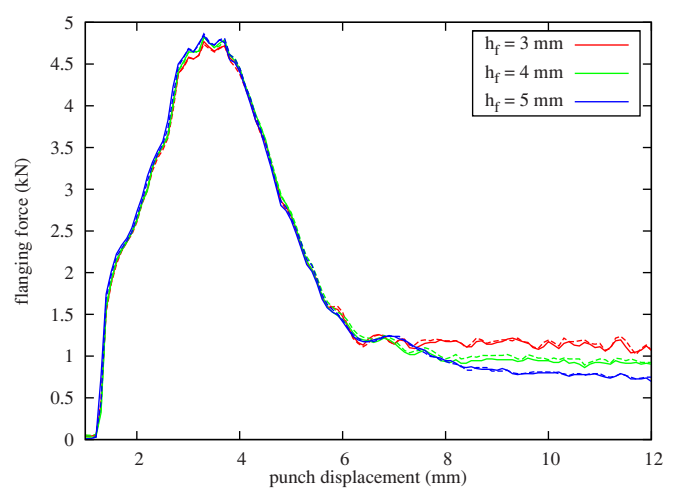

(a) flanging force vs punch displacement for different edge heights $\left(h_{e}\right)$

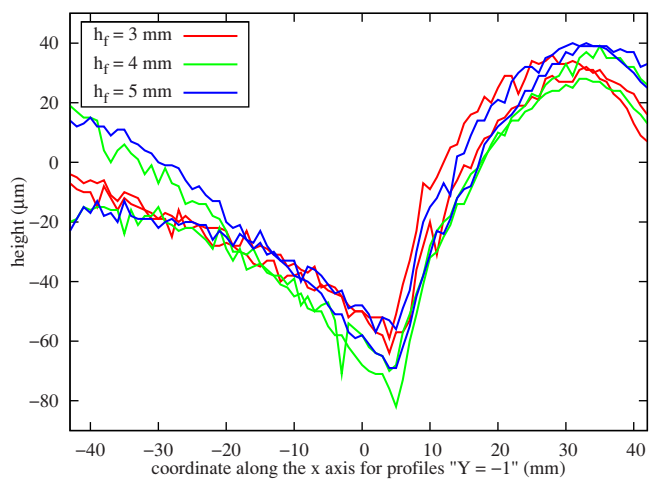

(b) profiles $\mathrm{y}=-1$ for different edge heights $\left(h_{e}\right)$

Fig. 8. Edge height influence on the flanging force and on the surface defect geometry

\subsection{Flanging speed influence}

The influence of flanging speed has been investigated using blanks with a constant flanging height of $3 \mathrm{~mm}$, i.e. without reduction of its value near the corner radius. The force-displacement curves (Fig. 9(a)) have similar shapes for a punch speed varying from $26 \times 10^{-3} \mathrm{~mm} . \mathrm{s}^{-1}$ to $374 \times 10^{-3} \mathrm{~mm} . \mathrm{s}^{-1}$, nevertheless at a speed of $14,100 \times 10^{-3} \mathrm{~mm} \cdot \mathrm{s}^{-1}$ the peak of effort increases by $10 \%$.

The geometrical results of the profiles " $y=-1$ " plotted in Fig. 9(b) exhibit identical shapes for speeds of $374 \times 10^{-3} \mathrm{~mm} \cdot \mathrm{s}^{-1}$ and $14,100 \times 10^{-3} \mathrm{~mm} \cdot \mathrm{s}^{-1}$. However, with $26 \times 10^{-3} \mathrm{~mm} \cdot \mathrm{s}^{-1}$ of punch speed the profile " $y=-1$ " is different at negative $x$ ordinates, it has a flat shape that decreases the depth of the surface defect. 
The flanging speed influence on the flanging force and on the surface defect geometry do not correlate, it is thus assumed that this parameter is of negligible effect on surface defects.

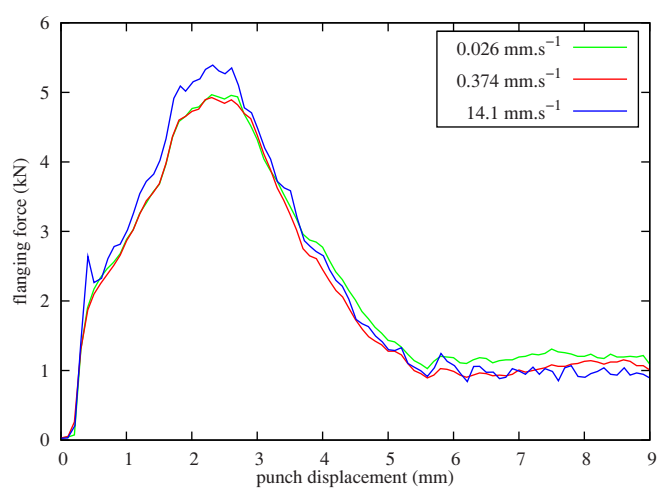

(a) flanging force vs punch displacement for different flanging speed

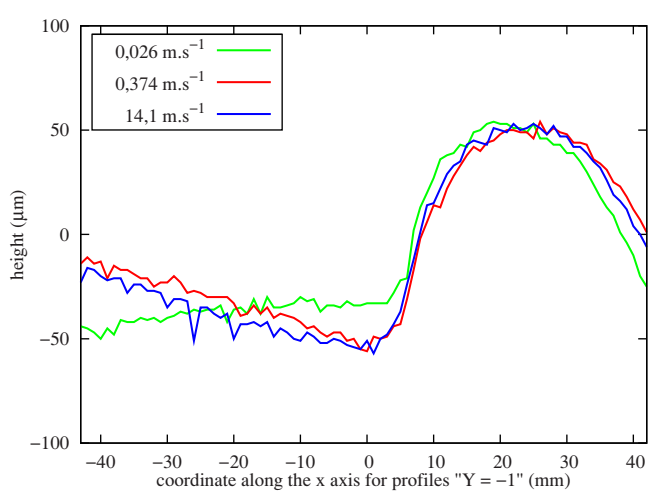

(b) profiles $\mathrm{y}=-1$ for different flanging speed

Fig. 9. Flanging speed influence on the flanging force and on the surface defect geometry

\subsection{Numerical simulations}

In order to investigate a wider range of parameters numerical simulation of the flanging operation has been developped using the finite-element code Abaqus. The results presented in this paper have been obtained with a blank meshed with six layers of solid hexahedral elements in the thickness and a maximum element size of $1 \mathrm{~mm}$, The tools are meshed with rigid shell elements. An elastic-plastic model with an anisotropic Hill 48 yield criterion and isotropic hardening is used to simulate the behavior of DP500 steel. The flanging process is simulated in two steps : flanging using explicit integration and springback using implicit integration.

A very good agreement between experimental and numerical efforts (Fig. 10(a)) is obtained thanks to two different friction coefficients, 0.3 on the flanging blade radius and 0.5 on the rest of the surfaces. On the other hand, the geometrical comparison (Fig.10(b)) shows poor agrement between experiments and simulation. The shapes of the profiles are well simulated but the vertical amplitudes are underestimated and the defect depth of $80 \mu \mathrm{m}$ becomes $40 \mu \mathrm{m}$. The use of shell elements allows to predict a slightly larger depth [4].

\section{Conclusions and perspectives}

Characterization of surface defects of automotive opening parts is the main aim of this study. A surface defect on a door upper-corner has been analyzed and its geometrical features have been measured in terms of depth, length and width. A simplified flanging device aimed to reproduce the door uppercorner surface defect has been designed for flat samples.

The material used in this study is a dual-phase DP500 steel of $0.6 \mathrm{~mm}$ thickness. Its mechanical behavior has been characterized with uniaxial tension, biaxial expansion and shear tests, in order to identify material parameters of Hill's 1948 yield criterion and an isotropic hardening law.

The surfaces of both the initial and the flanged blank have been measured on a three-dimensional measuring machine and the defect size is of the order of $80 \mu \mathrm{m}$ in depth and $40 \times 70 \mathrm{~mm}^{2}$ in the plane. The influence of the flanging height and the tool speed on the defect geometry has been investigated but no real dependance has been highlighted within the chosen range. 


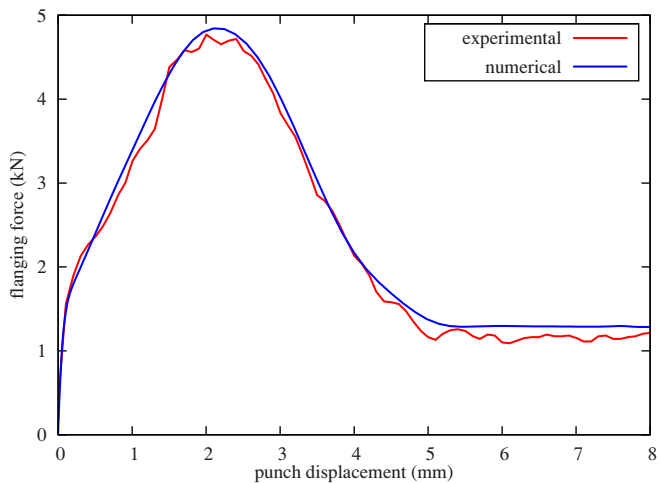

(a) flanging force vs punch displacement for different flanging speed

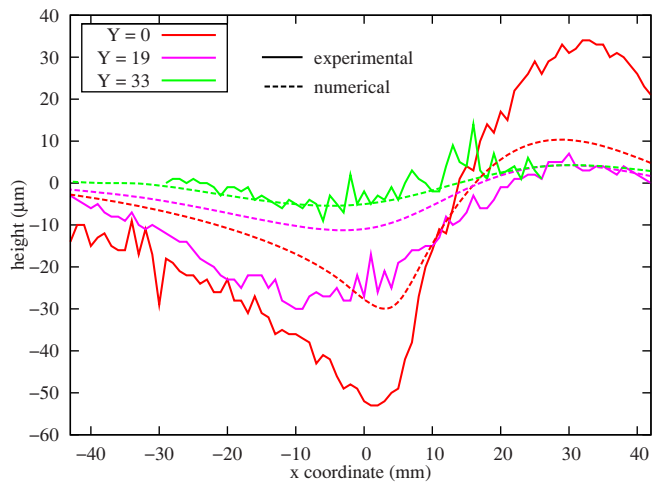

(b) profiles $\mathrm{y}=-1$ for different flanging speed

Fig. 10. Comparison of the flanging force and the surface defect geometry between experimental and numerical results

Numerical simulation of the flanging process is performed with a 3D model for the blank. Friction coefficients have been adjusted in order to reproduce the punch load evolution with the tool displacement. Numerical profiles have been post-treated similarly to the experimental ones: a surface defect can be observed but its magnitude is lower than the experimental one.

The results presented in this paper allowed to quantify a surface defect on a simple geometry, nevertheless the parameters studied exhibit no influence on the geometry of the defect, so other parameters will be studied such as the flanging radius or the corner radius. In order to be more reliable the numerical simulation needs to be improved, by the use of different elements or different behavior laws taking into account kinematic hardening or instability phenomenons.

\section{References}

1. Park C.D., Chung W.J., Kim B.M., J. Mater. Process. Technol. 187-188, (2007) 99-102.

2. Andersson A., J. Mater. Process. Technol. 209, (2009) 821-837.

3. A. Le Port, S. Thuillier, P.Y. Manach, J.Garabed, Numisheet (ETH Zurich, Interlaken, 2008) 773778.

4. A. Le Port, S. Thuillier, P.Y. Manach, Int. J. of Material Forming, (2009). 